\title{
White blood cell count predicts the odds of kidney function decline in a Chinese community-based population
}

Fangfang Fan, Jia Jia, Jianping Li, Yong Huo ${ }^{*}$ and Yan Zhang ${ }^{*}$

\begin{abstract}
Background: Inflammatory processes are very important in the development of kidney disease. Nevertheless, the association between white blood cell (WBC) count and the risk of renal dysfunction has not been well-established, especially in subjects without chronic kidney disease (CKD). Our study investigated the association between WBC count and kidney function decline in a Chinese community-based population with baseline estimated glomerular filtration rate (eGFR) $\geq 60 \mathrm{~mL} / \mathrm{min} / 1.73 \mathrm{~m}^{2}$.
\end{abstract}

Methods: A total of 3768 subjects who were enrolled in an atherosclerosis cohort in Beijing were included in this study. EGFRs were calculated at baseline and follow-up using the CKD-EPI formula. The outcomes of this study were renal function decline (RFD) (a drop in eGFR stage along with a decline in eGFR of $25 \%$ or exceeding $5 \mathrm{~mL} / \mathrm{min} / 1$. $73 \mathrm{~m}^{2} /$ year), rapid eGFR decline (an annual decrease in eGFR exceeding $3 \mathrm{~mL} / \mathrm{min} / 1.73 \mathrm{~m}^{2}$ ), and incident CKD (eGFR $<60 \mathrm{~min} / 1.73 \mathrm{~m}^{2}$ at follow-up). Multivariate logistic regression models were used to evaluate the associations between WBC count and each outcome.

Results: On average, the subjects were $56.6 \pm 8.5$ years old, and $35.9 \%$ were male. Of the participants, $48.6 \%$ had hypertension and $17.4 \%$ had diabetes. The mean (SD) WBC count at baseline was $6.1 \pm 1.5 \times 10^{9} / \mathrm{L}$. The mean (SD) eGFR at baseline was $101.1 \pm 10.6 \mathrm{~mL} / \mathrm{min} / 1.73 \mathrm{~m}^{2}$. After 2.3 years follow-up, the incidence rates of RFD, rapid eGFR decline and new CKD were 7.7, 20.9, and $0.8 \%$, respectively. WBC count was significantly related to RFD, rapid eGFR decline and new CKD in the univariate analyses. Even after adjustment for demographic variables, comorbidities, medications and baseline eGFR, these associations remained. Moreover, similar trends in RFD were observed in nearly all subgroups stratified by each confounding variable. The increase in the odds of RFD associated with each $10^{9} / \mathrm{L}$ increase in WBC count was significantly greater in subjects not undergoing treatment with lipid-lowering drugs than those not undergoing this treatment (P-interaction: 0.05).

Conclusions: In conclusion, elevated WBC count served as a predictor of the odds of kidney function decline in this population, which supports the hypothesis that systemic inflammation may serve as a risk factor for CKD development.

Keywords: Chronic inflammation, Chronic renal failure, GFR, Prediction, White blood cell

\section{Background}

Chronic kidney disease (CKD) has increasingly become as a worldwide public health problem in the recent decades [1]. As a subgroup with high risk of developing cardiovascular disease (CVD), CKD have been found to share many similar traditional atherosclerosis risk factors

\footnotetext{
*Correspondence: huoyong@263.net.cn; drzhy1108@163.com Department of Cardiology, Peking University First Hospital, No. 8 Xishiku Street, Xicheng District, Beijing 100034, China
}

with CVD [2, 3]. Currently, CVD is regarded as an inflammatory disease $[4,5]$, and inflammatory markers are also involved in the development of hypertension [6] and diabetes mellitus [7], potentially indicating that atherosclerosis is a chronic inflammatory process [8]. Therefore, inflammation may also be implicated in the complex pathophysiological mechanisms of CKD, and identifying new modifiable risk factors for CKD at an early stage of kidney disease may help greatly in reducing the burden associated with this illness. 
Inflammatory processes have been suspected to play a key role in the development of kidney disease in both animal and human models [9]. Increasing evidence has suggested that several inflammatory markers, including white blood cell (WBC) counts and C-reactive protein (CRP), serum albumin, tumour necrosis factor receptor, ferritin and interleukin- 6 levels, may be associated with kidney function and could predict the risk of future kidney function loss and incident CKD [10-18].

However, inconsistent evidence has been reported regarding the relationship between WBC count, which is a traditional indicator of systemic inflammation, and kidney function decline, and this association may be influenced by race and gender [10-15]. Nevertheless, few studies have focused on this topic in Chinese populations [15]. Given the urgency of the epidemiological situation of CKD in China, which may be observed based on CKD prevalence rates that reached as high as $10.8 \%$ (119.5 million patients) between 2007 and 2010, as indicated by the results of the National Survey of Chronic Kidney Disease [19], we hoped to determine whether WBC count data were predictive of the odds of future renal function decline in the Chinese population.

Thus, this study aimed to assess the longitudinal associations between WBC count and the decline of kidney function and new-onset of CKD in a Chinese communitybased cohort with baseline preserved kidney function.

\section{Methods}

\section{Study population}

The participants included in this study were identified from subjects enrolled in an cohort survey focusing on atherosclerosis diseases conducted from December 2011 to July 2014 in Beijing, China. Detailed study procedures have been described previously [20]. Briefly, 5962 participants aged $\geq 40$ years who had received a baseline survey were invited to participated in a follow-up visit in $2014,3823(64.1 \%)$ of whom responded on site. The baseline characteristics of non-responders did not differ substantially from those of responders (data not shown). We further excluded participants for whom WBC count measurement data were not obtained at the follow-up visit and those who already had CKD at baseline. Finally, 3768 eligible participants were included in this analysis. This study was approved by the ethics committee of Peking University as well as the ethics committee of Peking University First Hospital, and each participant signed informed consent. We adhered to the principles of the Declaration of Helsinki. The procedures followed were in accordance with institutional guidelines.

\section{Data collection}

As described previously [20], trained research staff collected baseline data according to the standard operating procedure of the study. All participants were interviewed using a standardized questionnaire that included questions about demographic characteristics, health behaviour and medical history. Specifically, current smoker was defined as smoking one cigarette per day for at least half a year, and current drinker was defined as drinking once per week for at least half a year.

Body mass index (BMI) was calculated as weight (kilograms) divided by squared height (meters). Seated brachial blood pressure (BP) of each subject was obtained after a 5-min rest. Calibrated Omron HEM-7117 electronic sphygmomanometers were used to measure BP values. Triplicate measurements were measured on the right arm with at least a 1-min period between successive readings, and their averages were used further.

Blood samples were drawn from each subject's forearm in the morning after an overnight fasting period. Each patient's WBC count $\left(\times 10^{9} / \mathrm{L}\right)$ was measured using a BC-3000 auto haematology analyser (Mindray Medical International, Inc.) in the laboratory of Peking University Shougang Hospital. Baseline fasting blood glucose (FBG), $2 \mathrm{~h}$ glucose in the standard 75-g oral glucose tolerance test (OGTT), total cholesterol (TC), low-density lipoprotein (LDL) cholesterol, high-density lipoprotein (HDL) cholesterol, and triglycerides (TG) levels were measured using the Roche C8000 Automatic Analyser.

As described previously [20], serum creatinine levels $(\mu \mathrm{mol} / \mathrm{L})$ at baseline and follow-up were measured using the enzymatic method and Jaffe's kinetic method, respectively, then transformed using the enzymatic equation, and finally calibrated to the values of one core laboratory. EGFR was estimated using the equation developed by the Chronic Kidney Disease Epidemiology Collaboration (CKD-EPI) [21].

\section{Outcomes}

The Renal function decline (RFD) was the primary outcome in this study. It was defined according to the Kidney Disease: Improving Global Outcome (KDIGO) 2012 definition [22] as follows: "a drop in the GFR category and accompanied by a $25 \%$ or greater drop in eGFR from baseline or a sustained decline in eGFR of more than $5 \mathrm{~mL} / \mathrm{min} / 1.73 \mathrm{~m}^{2} /$ year."

The secondary outcomes in this study were (1) rapid eGFR decline, which was defined as a decline in eGFR exceeding $3 \mathrm{~mL} / \mathrm{min} / 1.73 \mathrm{~m}^{2} /$ year $[11,23]$, and (2) newonset CKD, which was defined as an eGFR below $60 \mathrm{~mL} / \mathrm{min} / 1.73 \mathrm{~m}^{2}$ measured at follow-up survey.

\section{Statistical analysis}

Hypertension was defined as either self-reported hypertension history or a SBP $\geq 140 \mathrm{mmHg}$ or DBP $\geq 90 \mathrm{mmHg}$ at baseline. Diabetes mellitus was defined as either self-reported diabetes history or simultaneous identification of an FBG level $\geq 7.0 \mathrm{mmol} / \mathrm{L}$ and OGTT value 
$\geq 11.1 \mathrm{mmol} / \mathrm{L}$. Dyslipidaemia was defined as any selfreported history of hyperlipidaemia or a TG level $\geq 1.70 \mathrm{mmol} / \mathrm{L}(150 \mathrm{mg} / \mathrm{dL})$, TC level $\geq 5.18 \mathrm{mmol} / \mathrm{L}$ (200 mg/dL), LDL-C level > $3.37 \mathrm{mmol} / \mathrm{L}(130 \mathrm{mg} / \mathrm{dL})$ or HDL-C level $<1.04 \mathrm{mmol} / \mathrm{L}(40 \mathrm{mg} / \mathrm{dL})$. CVD was defined as any self-reported suffering from coronary heart disease, stroke, or transient ischaemic attack previously.

Data were expressed as the mean (standard deviation, SD) for continuous variables and percentages (\%) for categorical variables. Normally distributed continuous variables were compared using one-way ANOVA tests. Categorical variables were compared using the Pearson X2 test. WBC count was examined as both continuous and categorical (quartiles) variables. Univariate and multivariate Logistic regression models were generated to investigate the effects of WBC count on the occurrence of all outcomes. Covariates were selected based on previous studies relating to WBC count or renal function. The odds of renal outcomes were evaluated in association with $10^{9} / \mathrm{L}$ increases and quartiles of WBC count.

A subgroup analysis was performed to examine the associations between WBC count and the odds of all outcomes following adjustment for sex, age, BMI, baseline eGFR, current smoking, current drinking, hypertension, diabetes mellitus, dyslipidaemia, history of CVD, antihypertensive drug use, hypoglycaemic drug use, and lipidlowering drug use. Interaction terms were entered into the logistic regression models to compare the effects of WBC count on each outcome between the analysed subgroups.

We also performed sensitivity analyses excluding subjects with WBC counts not in the normal range $\left(4.0-10.0 \times 10^{9} / \mathrm{L}\right)$, reflecting the possible influence of acute infectious diseases and haematological system diseases.

A $P$-value of $<0.05$ (two-sided) was considered statistically significant for all tests. All analyses were performed using Empower(R) (www.empowerstats.com, X\&Y solutions, Inc. Boston MA) and R (http://www.R-project.org).

\section{Results}

Table 1 showed the baseline characteristics of the participants overall and stratified by WBC count quartiles. The mean age of the participants was $56.6 \pm 8.5$ years. Of the participants, $35.9 \%$ were male, and the mean (SD) BMI was $26.0 \pm 3.4 \mathrm{~kg} / \mathrm{m}^{2}$. Hypertension was present in $48.6 \%$ of all participants, whereas 17.4 and $75.1 \%$ of the participants had diabetes mellitus and dyslipidaemia, respectively. The prevalence of CVD was $12.3 \%$. The mean (SD) baseline WBC count was $6.1 \pm 1.5 \times 10^{9} / \mathrm{L}$, and the mean (SD) baseline eGFR was $101.1 \pm 10.6 \mathrm{~mL} / \mathrm{min} /$ $1.73 \mathrm{~m}^{2}$. Subjects with higher WBC counts were more likely to be male; had significantly higher BMIs; had higher prevalence rates of hypertension, diabetes mellitus, dyslipidaemia, and CVD; more frequently used antihypertensive drugs, hypoglycaemic drugs and lipid-lowering drugs; and had lower baseline eGFR levels.

After a mean follow-up of 2.4 years (median: 2.3; 25th centile-75th centile: $2.1-2.6$ ), the incidence rates of RFD, rapid eGFR decline and new CKD were 7.7, 20.9, and $0.8 \%$, respectively. The odds of RFD, rapid eGFR decline and new CKD gradually increased with increasing WBC counts (Table 2).

TThe effects of WBC count on all outcomes in the multivariate regression analysis are displayed in Table 3. The odds of RFD, rapid eGFR decline and new CKD were positively related to $\mathrm{WBC}$ count, and these relationships remained statistically significant after adjustment for age, sex, baseline eGFR and various other baseline parameters. ORs (95\% confidence interval, CI) of 1.14 (1.06, 1.23), $1.11(1.05,1.17)$ and $1.36(1.11,1.68)$ were identified in association with each $10^{9} / \mathrm{L}$ increase in WBC count for RFD, rapid eGFR decline and new CKD, respectively. The odds of RFD, rapid eGFR decline and new CKD also demonstrated consistent dose-dependent relationships with the WBC count quartiles (OR [95\% CI] for highest versus lowest quartile: $2.01[1.38,2.93] ; 1.49$ [1.17, 1.91]; 4.79 [1.00, 23.00]; P-trend: $<0.001 ;<0.001 ; 0.018)$.

The results of the subgroup analyses are presented in Table 4. No significant heterogeneity was observed across nearly all of the subgroups defined according to sex; age ( $<60$ or $\geq 60$-year-old); BMI $\left(<28\right.$ or $\left.\geq 28 \mathrm{~kg} / \mathrm{m}^{2}\right)$; baseline eGFR (<the median value of 102.5 or $\geq 102.5 \mathrm{~mL} / \mathrm{min}$ / $1.73 \mathrm{~m}^{2}$ ); current smoking; current drinking; prevalence of hypertension, diabetes mellitus, dyslipidaemia and CVD; and usage of antihypertensive drugs, hypoglycaemic drugs and lipid-lowering drugs. However, the increase in the odds of rapid eGFR decline associated with each $10^{9} / \mathrm{L}$ increase in WBC was significantly greater in older than younger subjects $(\mathrm{P}$-interaction $=0.04)$. Meanwhile, the increases in the odds of RFD (OR $=1.18,95 \%$ CI: 1.09 1.28, P-interaction $=0.05)$, rapid eGFR decline $(\mathrm{OR}=1.13$, 95\% CI: 1.07-1.20, P-interaction $=0.09)$ and new $\mathrm{CKD}$ $(\mathrm{OR}=1.54,95 \% \mathrm{CI}: 1.20-1.96, \mathrm{P}$-interaction $=0.07)$ associated with each $10^{9} / \mathrm{L}$ increase of WBC count were significantly greater in those not undergoing treatment with lipid-lowering drugs than those undergoing such treatment; however, the $P$-values for these interactions were only borderline significant.

The results of the sensitivity analysis in which subjects with WBC count not in the normal range (4.0$\left.10.0 \times 10^{9} / \mathrm{L}\right)$ were excluded are shown in Additional file 1: Table S1. Similar results were identified in this sensitivity analysis.

\section{Discussion}

The main findings of our study were as follows: WBC count, a traditional indicator of systemic inflammation, 
Table 1 Baseline characteristics of the study cohort

\begin{tabular}{|c|c|c|c|c|c|c|}
\hline \multirow[t]{3}{*}{ Variables } & \multicolumn{6}{|c|}{ White blood cell, $10^{9} / \mathrm{L}$} \\
\hline & \multirow{2}{*}{$\begin{array}{l}\text { All } \\
N=3768\end{array}$} & \multirow{2}{*}{$\begin{array}{l}\text { Quartile } 1 \\
(<5.0) \\
N=835\end{array}$} & \multirow{2}{*}{$\begin{array}{l}\text { Quartile } 2 \\
(5.0-6.0) \\
N=1047\end{array}$} & \multirow{2}{*}{$\begin{array}{l}\text { Quartile } 3 \\
(6.0-7.0) \\
N=925\end{array}$} & \multirow{2}{*}{$\begin{array}{l}\text { Quartile } 4 \\
(\geq 7.0) \\
N=961\end{array}$} & \multirow[t]{2}{*}{ P-treno } \\
\hline & & & & & & \\
\hline Age, year & $56.6(8.5)$ & $56.3(8.0)$ & $56.5(8.5)$ & $56.9(8.5)$ & $56.8(9.0)$ & 0.149 \\
\hline Males, $n(\%)$ & $1352(35.9 \%)$ & $203(24.3 \%)$ & $356(34.0 \%)$ & $336(36.3 \%)$ & $457(47.6 \%)$ & $<0.001$ \\
\hline White blood cell, $10^{9} / \mathrm{L}$ & $6.1(1.5)$ & $4.4(0.5)$ & $5.5(0.3)$ & $6.4(0.3)$ & $8.2(1.2)$ & $<0.001$ \\
\hline Body mass index, $\mathrm{kg} / \mathrm{m}^{2}$ & $26.0(3.4)$ & $25.3(3.3)$ & $25.9(3.2)$ & $26.2(3.4)$ & $26.6(3.4)$ & $<0.001$ \\
\hline eGFR, $\mathrm{mL} / \mathrm{min} / 1.73 \mathrm{~m}^{2}$ & $101.1(10.6)$ & $101.9(10.1)$ & $101.4(10.0)$ & $101.0(10.6)$ & $100.2(11.8)$ & 0.001 \\
\hline Current smoking status, n (\%) & 709 (18.8\%) & $82(9.8 \%)$ & $164(15.7 \%)$ & $168(18.2 \%)$ & $295(30.7 \%)$ & $<0.001$ \\
\hline Current drinking status, $n(\%)$ & $868(23.0 \%)$ & 145 (17.4\%) & $257(24.5 \%)$ & $221(23.9 \%)$ & $245(25.5 \%)$ & $<0.001$ \\
\hline \multicolumn{7}{|l|}{ Prevalence of disease, $n(\%)$} \\
\hline Hypertension & $1833(48.6 \%)$ & $355(42.5 \%)$ & $500(47.8 \%)$ & $466(50.4 \%)$ & $512(53.3 \%)$ & $<0.001$ \\
\hline Diabetes mellitus & $654(17.4 \%)$ & $105(12.6 \%)$ & $153(14.6 \%)$ & $167(18.1 \%)$ & $229(23.8 \%)$ & $<0.001$ \\
\hline Dyslipidemia & $2768(75.1 \%)$ & $567(69.6 \%)$ & $739(72.3 \%)$ & 709 (78.4\%) & 753 (79.8\%) & $<0.001$ \\
\hline Cardiovascular disease & 477 (12.7\%) & $82(9.8 \%)$ & $119(11.4 \%)$ & $132(14.3 \%)$ & $144(15.0 \%)$ & $<0.001$ \\
\hline \multicolumn{7}{|l|}{ Treatment, n (\%) } \\
\hline Antihypertensive & $1183(31.6 \%)$ & $197(23.8 \%)$ & $323(31.0 \%)$ & 315 (34.2\%) & $348(36.4 \%)$ & $<0.001$ \\
\hline Hypoglycemic & $382(10.2 \%)$ & $62(7.4 \%)$ & $88(8.4 \%)$ & 105 (11.4\%) & $127(13.3 \%)$ & $<0.001$ \\
\hline Lipid-lowering & $397(10.6 \%)$ & 59 (7.1\%) & $104(10.0 \%)$ & 109 (11.9\%) & $125(13.1 \%)$ & $<0.001$ \\
\hline
\end{tabular}

Abbreviations: eGFR estimated glomerular filtration rate

was significantly associated with the odds of future RFD, rapid eGFR decline and incident CKD even after adjusting for known atherosclerosis risk factors such as age, sex, BMI, lifestyles, comorbidities, and medications, and baseline eGFR in this Chinese community-based population with preserved kidney function (eGFR $\geq 60 \mathrm{~mL} / \mathrm{min}$ / $1.73 \mathrm{~m}^{2}$ ) at baseline. After a mean follow-up 2.4 years, subjects with the highest quartile of WBC count were at 1.49-fold greater odds of rapid eGFR decline, 2.01-fold greater odds of RFD, and 4.79-fold greater odds of new incident CKD. Detection of higher WBC counts in an early stage may be valuable for CKD risk assessment and prevention.

Low-grade inflammation has been found to be common in patients with CKD and end-stage renal disease (ESRD) and has already been recognized as playing a unique role in the pathophysiology and taking account for the future CVD and all-cause mortality risk [24]. However, inconsistent evidence has been presented regarding whether inflammation markers, including WBC count, may be used to predict the risk of future kidney function decline. In the NHANES II, a nationally representative cohort of 9250 US adults with 17 years' followup, WBC counts were found to be positive related to the risk of future CKD, defined as ESRD treatment or death due to kidney disease (relative hazard, 2.01, 95\% CI, 1.11 to 3.65 for the highest versus lowest quartile) [10]. Additionally, data from the Cardiovascular Health Study (CHS) revealed that higher WBC counts could independently predict annual increases in serum creatinine or declines in eGFR in a community-based cohort of 5888 elderly individuals with 4 to 7 years' follow-up [11]. Similar findings were also identified in data from the following two long-term population-based cohorts in the

Table 2 Renal function decline, rapid eGFR decline and incident CKD according to white blood cell quartiles

\begin{tabular}{clll}
\hline White blood cell & Renal function decline & Rapid eGFR decline & Incident CKD \\
\hline All & $292(7.7 \%)$ & $787(20.9 \%)$ & $30(0.8 \%)$ \\
Quartile 1 & $52(6.2 \%)$ & $153(18.3 \%)$ & $3(0.4 \%)$ \\
Quartile 2 & $67(6.4 \%)$ & $205(19.6 \%)$ & $5(0.5 \%)$ \\
Quartile 3 & $73(7.9 \%)$ & $195(21.1 \%)$ & $6(0.6 \%)$ \\
Quartile 4 & $100(10.4 \%)$ & $234(24.3 \%)$ & $16(1.7 \%)$ \\
P-trend & $<0.001$ & 0.001 & 0.002 \\
\hline
\end{tabular}


Table 3 Multivariate regression for the effect of white blood cell on renal function decline, rapid eGFR decline and incident CKD

\begin{tabular}{|c|c|c|c|}
\hline \multirow[t]{2}{*}{ Variables } & Crude model & Adjusted model 1 & Adjusted model 2 \\
\hline & OR $(95 \% \mathrm{Cl})$ & OR $(95 \% \mathrm{Cl})$ & OR $(95 \% \mathrm{Cl})$ \\
\hline \multicolumn{4}{|l|}{ Renal function decline } \\
\hline WBC continuous, $10^{9} / \mathrm{L}$ & $1.12(1.04,1.20)$ & $1.14(1.06,1.22)$ & $1.14(1.06,1.23)$ \\
\hline \multicolumn{4}{|l|}{ WBC quartiles } \\
\hline Quartile 1 & 1(Reference) & 1(Reference) & 1 (Reference) \\
\hline Quartile 2 & $1.03(0.71,1.50)$ & $1.06(0.73,1.54)$ & $1.07(0.72,1.60)$ \\
\hline Quartile 3 & $1.29(0.89,1.87)$ & $1.34(0.92,1.94)$ & $1.45(0.99,2.15)$ \\
\hline Quartile 4 & $1.75(1.23,2.48)$ & $1.89(1.32,2.69)$ & $2.01(1.38,2.93)$ \\
\hline P-trend & $<0.001$ & $<0.001$ & $<0.001$ \\
\hline \multicolumn{4}{|l|}{ Rapid eGFR decline } \\
\hline WBC continuous, $10^{9} / \mathrm{L}$ & $1.10(1.04,1.15)$ & $1.12(1.06,1.18)$ & $1.11(1.05,1.17)$ \\
\hline \multicolumn{4}{|l|}{ WBC quartiles } \\
\hline Quartile 1 & 1(Reference) & 1(Reference) & 1 (Reference) \\
\hline Quartile 2 & $1.09(0.86,1.37)$ & $1.12(0.89,1.42)$ & $1.11(0.87,1.41)$ \\
\hline Quartile 3 & $1.19(0.94,1.51)$ & $1.24(0.98,1.57)$ & $1.20(0.94,1.54)$ \\
\hline Quartile 4 & $1.43(1.14,1.80)$ & $1.58(1.25,1.99)$ & $1.49(1.17,1.91)$ \\
\hline P-trend & 0.001 & $<0.001$ & $<0.001$ \\
\hline \multicolumn{4}{|l|}{ Incident CKD } \\
\hline WBC continuous, $10^{9} / \mathrm{L}$ & $1.41(1.20,1.64)$ & $1.33(1.09,1.62)$ & $1.36(1.11,1.68)$ \\
\hline \multicolumn{4}{|l|}{ WBC quartiles } \\
\hline Quartile 1 & 1(Reference) & 1(Reference) & 1(Reference) \\
\hline Quartile 2 & $1.33(0.32,5.58)$ & $1.35(0.30,6.02)$ & $1.72(0.29,10.25)$ \\
\hline Quartile 3 & $1.81(0.45,7.26)$ & $1.73(0.41,7.37)$ & $2.11(0.38,11.68)$ \\
\hline Quartile 4 & $4.70(1.36,16.17)$ & $3.30(0.90,12.09)$ & $4.79(1.00,23.00)$ \\
\hline P-trend & 0.002 & 0.031 & 0.018 \\
\hline
\end{tabular}

Model 1: adjusted for age, sex, and eGFR at baseline

Model 2: adjusted for variables in model 1 and body mass index, current smoking, current drinking, hypertension, diabetes mellitus, dyslipidemia, history of cardiovascular disease, antihypertensive drugs, hypoglycemic drugs, and lipid-lowering drugs

Abbreviations: WBC white blood cell, eGFR estimated glomerular filtration rate, CKD chronic kidney disease, OR odd ratio, $C I$ confidence interval

US: 14,854 middle-aged adults from 4 different communities with a mean follow-up of almost $14 \quad 1 / 2$ years (ARIC) [12] and 4926 subjects from the Beaver Dam CKD study with 15 years of follow-up [13].

However, in the ARIC study, WBC count was found to be a better predictor of CKD risk stronger in African Americans relative to whites (Hazard Ratios [95\% CI]: 1.14 [1.07-1.23] vs. 1.10 [1.04-1.17] for 1-SD increment, P-interaction $=0.08$ for continuous $\mathrm{WBC}$ count and 0.004 for race-specific WBC quartiles) [12]. Furthermore, sex differences for the association between WBC count and CKD were identified in a cohort in 2825 Korean adults from the 2007 Korean National Health and Nutrition Examination Survey. In this study, a significant association was only identified in women [14]. In addition, high sensitivity CRP and ferritin levels but not WBC count were found to be associated with increased odds of both renal replacement therapy and rapid renal decline in 3303 Chinese patients with stage 3-5 CKD after a mean follow-up period of 3.2 years [15]. The reason for the identification of inconclusive results in the aforementioned studies might be the significantly different populations studied.

Until now, the potential mechanisms by which inflammation processes lead to the development of CKD were not clear. Evidence has shown that inflammation has been hypothesized to play an important role in systemic atherosclerosis development $[4,5,8]$. Some may speculate that WBC counts are predictive of the risk of future CKD because of their relationships with many other atherosclerosis risk factors, like smoking, diabetes or hypertension [6, 7]. Adipose tissue can also be regarded as a source of inflammation [25]. Given the amount of literature regarding the associations between elevated WBC count and atherosclerotic disease and atherosclerotic disease and CKD, the positive relationship observed between WBC count and kidney function decline in our study may indicate association but not necessarily 
Table 4 Subgroup analysis for effect of white blood cell on risks of renal function decline, rapid eGFR decline or incident CKD

\begin{tabular}{|c|c|c|c|c|c|c|c|c|c|}
\hline \multirow[t]{2}{*}{ Variable } & \multicolumn{3}{|c|}{ Renal Function Decline } & \multicolumn{3}{|c|}{ Rapid eGFR Decline } & \multicolumn{3}{|c|}{ Incident CKD } \\
\hline & $\begin{array}{l}\text { Incidence, } \\
n(\%)\end{array}$ & OR $(95 \% \mathrm{Cl})$ & P-interaction & $\begin{array}{l}\text { Incidence, } \\
n(\%)\end{array}$ & OR $(95 \% \mathrm{Cl})$ & P-interaction & $\begin{array}{l}\text { Incidence, } \\
n(\%)\end{array}$ & OR $(95 \% \mathrm{Cl})$ & P-interaction \\
\hline \multicolumn{10}{|l|}{ Sex } \\
\hline Male & $88(6.5 \%)$ & $1.10(0.97,1.26)$ & 0.5244 & $244(18.0 \%)$ & $1.11(1.01,1.21)$ & 0.9709 & $9(0.7 \%)$ & $1.57(1.06,2.32)$ & 0.4362 \\
\hline Female & $204(8.4 \%)$ & $1.16(1.06,1.27)$ & & $543(22.5 \%)$ & $1.11(1.04,1.18)$ & & $21(0.9 \%)$ & $1.30(1.02,1.66)$ & \\
\hline \multicolumn{10}{|l|}{ Age, years } \\
\hline$<60$ & $195(7.4 \%)$ & $1.10(1.00,1.21)$ & 0.1517 & $543(20.5 \%)$ & $1.07(1.00,1.14)$ & 0.0398 & $7(0.3 \%)$ & $1.51(1.00,2.27)$ & 0.5985 \\
\hline$\geq 60$ & $97(8.6 \%)$ & $1.23(1.09,1.39)$ & & $244(21.7 \%)$ & $1.20(1.09,1.32)$ & & $23(2.0 \%)$ & $1.32(1.03,1.69)$ & \\
\hline \multicolumn{10}{|l|}{$\mathrm{BMI}, \mathrm{kg} / \mathrm{m}^{2}$} \\
\hline$<28$ & $212(7.6 \%)$ & $1.13(1.03,1.23)$ & 0.6299 & 577 (20.6\%) & $1.12(1.06,1.19)$ & 0.4084 & $23(0.8 \%)$ & $1.30(1.02,1.67)$ & 0.4080 \\
\hline$\geq 28$ & $80(8.3 \%)$ & $1.18(1.02,1.36)$ & & $210(21.7 \%)$ & $1.07(0.96,1.18)$ & & $7(0.7 \%)$ & $1.61(1.04,2.47)$ & \\
\hline \multicolumn{10}{|c|}{$\begin{array}{l}\text { Baseline eGFR, mL/min/ } \\
1.73 \mathrm{~m}^{2}\end{array}$} \\
\hline Low $(<102.5)$ & $166(8.8 \%)$ & $1.18(1.07,1.31)$ & 0.2632 & $356(18.9 \%)$ & $1.13(1.05,1.22)$ & 0.4544 & $28(1.5 \%)$ & $1.38(1.11,1.72)$ & 0.8913 \\
\hline High ( $\geq 102.5)$ & $126(6.7 \%)$ & $1.09(0.97,1.22)$ & & $430(22.8 \%)$ & $1.09(1.01,1.17)$ & & $2(0.1 \%)$ & $1.31(0.57,2.97)$ & \\
\hline \multicolumn{10}{|l|}{ Current smoking } \\
\hline No & 247 (8.1\%) & $1.16(1.07,1.27)$ & 0.3243 & 677 (22.1\%) & $1.11(1.05,1.18)$ & 0.9003 & $27(0.9 \%)$ & $1.37(1.10,1.70)$ & 0.9942 \\
\hline Yes & $45(6.3 \%)$ & $1.06(0.89,1.26)$ & & $110(15.5 \%)$ & $1.10(0.98,1.24)$ & & $3(0.4 \%)$ & $1.37(0.76,2.48)$ & \\
\hline \multicolumn{10}{|l|}{ Current drinking } \\
\hline No & $238(8.2 \%)$ & $1.17(1.08,1.28)$ & 0.1173 & 640 (22.0\%) & $1.12(1.05,1.19)$ & 0.4544 & $25(0.9 \%)$ & $1.36(1.08,1.72)$ & 0.9549 \\
\hline Yes & $54(6.2 \%)$ & $1.01(0.84,1.21)$ & & 147 (16.9\%) & $1.06(0.95,1.20)$ & & $5(0.6 \%)$ & $1.38(0.86,2.22)$ & \\
\hline \multicolumn{10}{|l|}{ Hypertension } \\
\hline No & $112(5.8 \%)$ & $1.12(0.99,1.26)$ & 0.6203 & $346(17.9 \%)$ & $1.07(0.99,1.16)$ & 0.2295 & $4(0.2 \%)$ & $1.16(0.67,2.02)$ & 0.4416 \\
\hline Yes & $180(9.8 \%)$ & $1.16(1.05,1.28)$ & & $441(24.1 \%)$ & $1.14(1.06,1.22)$ & & $26(1.4 \%)$ & $1.44(1.12,1.84)$ & \\
\hline \multicolumn{10}{|l|}{ Diabetes mellitus } \\
\hline No & $207(6.6 \%)$ & $1.12(1.02,1.23)$ & 0.5148 & $570(18.3 \%)$ & $1.11(1.05,1.18)$ & 0.7693 & $18(0.6 \%)$ & $1.45(1.08,1.94)$ & 0.5844 \\
\hline Yes & 85 (13.0\%) & $1.18(1.04,1.34)$ & & $217(33.2 \%)$ & $1.09(0.99,1.21)$ & & $12(1.8 \%)$ & $1.29(0.94,1.76)$ & \\
\hline \multicolumn{10}{|l|}{ Dyslipidemia } \\
\hline No & $68(7.4 \%)$ & $1.19(1.02,1.39)$ & 0.5331 & $186(20.3 \%)$ & $1.10(0.99,1.22)$ & 0.8334 & $5(0.5 \%)$ & $1.62(0.95,2.75)$ & 0.5003 \\
\hline Yes & $215(7.8 \%)$ & $1.13(1.03,1.23)$ & & $583(21.1 \%)$ & $1.11(1.05,1.18)$ & & $25(0.9 \%)$ & $1.32(1.05,1.67)$ & \\
\hline \multicolumn{10}{|c|}{ Cardiovascular disease } \\
\hline No & $240(7.3 \%)$ & $1.14(1.05,1.24)$ & 0.9617 & $657(20.0 \%)$ & $1.10(1.04,1.17)$ & 0.6392 & $18(0.5 \%)$ & $1.44(1.09,1.89)$ & 0.5951 \\
\hline Yes & $52(10.9 \%)$ & $1.14(0.96,1.35)$ & & $130(27.3 \%)$ & $1.14(1.00,1.30)$ & & $12(2.5 \%)$ & $1.28(0.91,1.79)$ & \\
\hline \multicolumn{10}{|c|}{ Antihypertensive drugs } \\
\hline No & $165(6.4 \%)$ & $1.12(1.02,1.24)$ & 0.5696 & 477 (18.6\%) & $1.08(1.01,1.16)$ & 0.2454 & $7(0.3 \%)$ & $1.06(0.66,1.70)$ & 0.2017 \\
\hline Yes & $125(10.6 \%)$ & $1.17(1.04,1.31)$ & & $305(25.8 \%)$ & $1.15(1.06,1.26)$ & & $22(1.9 \%)$ & $1.47(1.16,1.86)$ & \\
\hline \multicolumn{10}{|c|}{ Hypoglycemic drugs } \\
\hline No & $239(7.1 \%)$ & $1.14(1.04,1.24)$ & 0.7537 & $648(19.2 \%)$ & $1.11(1.05,1.18)$ & 0.8791 & $20(0.6 \%)$ & $1.52(1.16,2.00)$ & 0.2124 \\
\hline Yes & $52(13.6 \%)$ & $1.17(0.99,1.38)$ & & $138(36.1 \%)$ & $1.10(0.97,1.25)$ & & $10(2.6 \%)$ & $1.12(0.72,1.74)$ & \\
\hline \multicolumn{10}{|c|}{ Lipid-lowering drugs } \\
\hline No & $255(7.6 \%)$ & $1.18(1.09,1.28)$ & 0.0541 & $679(20.4 \%)$ & $1.13(1.07,1.20)$ & 0.0872 & $24(0.7 \%)$ & $1.54(1.20,1.96)$ & 0.0677 \\
\hline Yes & $34(8.6 \%)$ & $0.94(0.74,1.19)$ & & $102(25.7 \%)$ & $0.99(0.86,1.15)$ & & $4(1.0 \%)$ & $0.84(0.40,1.75)$ & \\
\hline
\end{tabular}

Variables in the model: age, sex, eGFR at baseline, body mass index, current smoking, current drinking, hypertension, diabetes mellitus, dyslipidemia, history of cardiovascular disease, antihypertensive drugs, hypoglycemic drugs, and lipid-lowering drugs

Abbreviations: eGFR estimated glomerular filtration rate, CKD chronic kidney disease, OR odd ratio, $C l$ confidence interval 
causation. However, the main results were not changed or weakened after further adjusting for confounders, including smoking status, BMI, hypertension, diabetes and CVD. Additionally, many animal and in vitro inflammation experiments have provided pathways through which the inflammation process may play important roles in CKD development [26-28]. Nevertheless, there may be other parameters related to inflammation, atherosclerosis and CVD that are potential confounders not adjusted for in this study. Therefore, the predictive value of WBC count should be more comprehensively verified in other large populations, and the precise pathological mechanisms behind this association should be investigated in further studies.

In CKD patients, several interventions, such as general lifestyle modifications, dietary supplementation and pharmacological agents, have already been proposed to target inflammation [23, 29]. However, it is not clear whether these therapies can prevent kidney function decline at a stage of kidney disease at which CKD has not yet occurred. Statins, as important agents with plenty of evidence supporting their role in CVD prevention and treatment, may play an efficient role in terms of not only lipid-lowering but also anti-inflammatory effect. Based on this theory, CARE trial investigators performed a post hoc analysis to examine the association between pravastatin use, inflammatory markers and the rate of kidney function decline, and found that the rate of renal function loss was $0.8 \mathrm{~mL} / \mathrm{min} / 1.73 \mathrm{~m}^{2} /$ year lower in pravastatin than placebo group $(P=0.039)$; this study followed 108 subjects for 58 months, and the results suggested that those with the highest level of inflammatory markers derived greater renal benefits from pravastatin than did those with low levels (P-interaction $=0.047$ ) [30]. Likewise, the results of the LORD trial, an RCT including 117 patients with serum creatinine levels $>120 \mu \mathrm{ml} / \mathrm{L}$ who were followed for an average of 2.5 years, demonstrated that CKD patients with high levels of inflammatory makers who were treated with atorvastatin had significantly lower eGFR declines [31]. Similarly, our data also suggested that subject using lipid-lowering drugs were more likely to have lower odds of future RFD, rapid eGFR decline and new CKD for each $10^{9} / \mathrm{L}$ increase in WBC count than were those not using these drugs, although the P-interaction were borderline significance. However, the results of the SHARP study suggested that lowering LDL-C by approximately $1 \mathrm{mmol} / \mathrm{L}$ for approximately 5 years through the use of lipid-lowering treatment had no significant effect on the rate of eGFR change among 6245 nondialysis participants with CKD; however, the effect of this treatment in patients with elevated inflammatory markers was not evaluated and worthy of further exploration [32].

Our study has several limitations. First, we did not assess other more sensitive markers of inflammation, such as the erythrocyte sedimentation rate or high sensitivity CRP, tumour necrosis factor-alpha and plasminogen activator inhibitor-1 levels at baseline [33], and related analyses were not available. Second, urinary albumin was used to define CKD, which has already been recognized as an important predictor of kidney function decline especially, in diabetes patients. We did not examine the albumin-creatinine ratio or urine dipstick results at baseline and, therefore, were not able to evaluate these factors, and we could not exclude patients with eGFRs $\geq 60 \mathrm{~mL} / \mathrm{min} / 1.73 \mathrm{~m}^{2}$ but abnormal urinary albumin levels from our analysis. However, no significant heterogeneity was identified in subgroup analysis according to diabetes status. Third, WBC count can be affected by acute infectious diseases; chronic inflammation processes; haematological system diseases; nutritional status; allergies; and medications, such as glucocorticoids, and these may have served as confounding factors. Therefore, we further performed a sensitivity analysis including a subset of patients with WBCs in the normal range, and the results were unchanged. Fourth, monocyte count has been found to be related to the risk of incident CKD and progression to ESRD [34]. However, we did not have the data on monocyte count and were not able to perform related analyses. Lastly, our study included only Chinese participants and may not be generalizable to other race-ethnic populations.

\section{Conclusions}

In conclusion, the results of our study demonstrate that WBC count, a traditional indicator of systemic inflammation, may predict the odds of future kidney function decline in a Chinese community-based population with normal kidney function. Prospective assessment of WBC count may help to promote the recognition of patients at high risk of kidney function decline. Interventions that may potentially reduce inflammation might also confer potential renal benefits. Further studies should focus on the precise pathological mechanisms behind this association and take inflammation as a treatment target to investigate its potential preventive effects on kidney disease.

\section{Additional file}

Additional file 1: Table S1. Multivariate regression for the effect of white blood cell on renal function decline, rapid eGFR decline and incident CKD in subjects with WBC count in normal range (DOC $48 \mathrm{~kb}$ )

\section{Abbreviations}

BMI: Body mass index; BP: Blood pressure; CKD: Chronic kidney disease; CVD: Cardiovascular disease; HDL: High-density lipoprotein; LDL: Low-density lipoprotein; OGTT: 75-g oral glucose tolerance test; RFD: Renal function decline; TC: Total cholesterol; TG: Triglycerides; WBC: White blood cell 


\section{Acknowledgements}

We thank all study team members for implementation and cooperation. We are also grateful for the organization by site managers Dr. Shuyu Wang and Dr. Liguang Dong.

\section{Funding}

This study was supported by grant from the UM-PUHSC joint institute for translational and clinical research (grant No: BMU20110177). The funders had no role in the design of the study and collection, analysis, and interpretation of data and in writing the manuscript.

\section{Availability of data and materials}

We are sorry to inform you that we cannot accept the data sharing policy due to the lack of consent from other cooperating research partners.

\section{Authors' contributions}

Prof $\mathrm{YZ}$ and Prof $\mathrm{YH}$ had full access to all of the data in the study and take responsibility for the integrity of the data and the accuracy of the data analysis. Study concept and design: YZ, JL, YH. Conduct of study: YZ, FF, JJ. Data management and statistical analysis: $F F$, JJ. Drafting of the manuscript: FF. Review and revision of the article: YZ, YH, JL, JJ, FF. The final manuscript has been reviewed and approved by all authors.

\section{Competing interests}

The authors declare that they have no competing interests.

\section{Consent for publication}

Not applicable.

\section{Ethics approval and consent to participate}

This study was approved by the ethics committee of Peking University and Peking University First Hospital, and each participant provided written informed consent. We adhered to the principles of the Declaration of Helsinki. The procedures followed were in accordance with institutional guidelines.

\section{Publisher's Note}

Springer Nature remains neutral with regard to jurisdictional claims in published maps and institutional affiliations.

\section{Received: 24 January 2017 Accepted: 31 May 2017}

\section{Published online: 07 June 2017}

\section{References}

1. Levey AS, Atkins R, Coresh J, Cohen EP, Collins AJ, Eckardt KU, et al. Chronic kidney disease as a global public health problem: approaches and initiatives a position statement from kidney disease Improving global outcomes. Kidney Int. 2007:72:247-59

2. Muntner P, He J, Astor B, Folsom A, Coresh J. Traditional and nontraditional risk factors predict coronary heart disease in chronic kidney disease: results from the atherosclerosis risk in communities study. J Am Soc Nephrol. 2005; 16:529-38.

3. Foley RN, Wang C, Collins AJ. Cardiovascular risk factor profiles and kidney function stage in the U.S. general population: the NHANES III study. Mayo Clin Proc. 2005:80:1270-7.

4. Sabatine MS, Morrow DA, Cannon CP, Murphy SA, Demopoulos LA, DiBattiste PM, et al. Relationship between baseline white blood cell count and degree of coronary artery disease and mortality in patients with acute coronary syndromes: a TACTICS-TIMI 18 (Treat Angina with Aggrastat and determine Cost of Therapy with an Invasive or Conservative Strategy- Thrombolysis in Myocardial Infarction 18 trial)substudy. J Am Coll Cardiol. 2002;40:1761-8.

5. Grau AJ, Boddy AW, Dukovic DA, Buggle F, Lichy C, Brandt T, et al. Leukocyte count as an independent predictor of recurrent ischemic events. Stroke. 2004;35:1147-52.

6. Shankar A, Klein BE, Klein R. Relationship between white blood cell count and incident hypertension. Am J Hypertens. 2004;17:233-9.

7. Schmidt Ml, Duncan BB, Sharrett AR, Lindberg G, Savage PJ, Offenbacher S, et al Markers of inflammation and prediction of diabetes mellitus in adults (atherosclerosis risk in communities study): a cohort study. Lancet. 1999;353:1649-52.

8. Libby P. Inflammation in atherosclerosis. Nature. 2002;420:868-74.
9. Ernandez T, Mayadas TN. The changing landscape of renal inflammation. Trends Mol Med. 2016;22:151-63.

10. Erlinger TP, Tarver-Carr ME, Powe NR, Appel LJ, Coresh J, Eberhardt MS, et al. Leukocytosis, hypoalbuminemia, and the risk for chronic kidney disease in US adults. Am J Kidney Dis. 2003:42:256-63.

11. Fried L, Solomon C, Shlipak M, Seliger S, Stehman-Breen C, Bleyer AJ, et al. Inflammatory and prothrombotic markers and the progression of renal disease in elderly individuals. J Am Soc Nephrol. 2004;15:3184-91.

12. Bash LD, Erlinger TP, Coresh J, Marsh-Manzi J, Folsom AR, Astor BC. Inflammation, hemostasis, and the risk of kidney function decline in the atherosclerosis risk in communities (ARIC) study. Am J Kidney Dis. 2009;53:596-605.

13. Shankar A, Sun L, Klein BE, Lee KE, Muntner P, Nieto FJ, et al. Markers of inflammation predict the long-term risk of developing chronic kidney disease: a population-based cohort study. Kidney Int. 2011:80:1231-8.

14. Na HY, Shim JY, Lee HR, Jung DH, Kim HB, Park BJ, et al. Sex differences in the relationship between leukocyte count and chronic kidney disease: the 2007 Korean National Health and nutrition examination survey. J Women's Health (Larchmt). 2011;20:99-105.

15. Tsai YC, Hung CC, Kuo MC, Tsai JC, Yeh SM, Hwang SJ, et al. Association of hsCRP, white blood cell count and ferritin with renal outcome in chronic kidney disease patients. Plos One. 2012;7:e52775.

16. Medenwald D, Girndt M, Loppnow H, Kluttig A, Nuding S, Tiller D, et al. Inflammation and renal function after a 4-year follow-up in subjects with unimpaired glomerular filtration rate: results from the observational, population-based CARLA cohort. Plos One. 2014;9:e108427.

17. Sinha SK, Shaheen M, Rajavashisth TB, Pan D, Norris KC, Nicholas SB. Association of race/ethnicity, inflammation, and albuminuria in patients with diabetes and early chronic kidney disease. Diabetes Care. 2014;37:1060-8.

18. Costello-White R, Ryff CD, Coe CL. Aging and low-grade inflammation reduce renal function in middle-aged and older adults in Japan and the USA. Age (Dordr). 2015; 37: 9808.

19. Zhang L, Wang F, Wang L, Wang W, Liu B, Liu J, et al. Prevalence of chronic kidney disease in China: a cross-sectional survey. Lancet. 2012:379:815-22.

20. Fan F, Qi L, Jia J, Xu X, Liu Y, Yang Y, et al. Noninvasive central systolic blood pressure is more strongly related to kidney function decline than peripheral systolic blood pressure in a Chinese community-based population. Hypertension. 2016;67:1166-72.

21. Levey AS, Stevens LA, Schmid CH, Zhang YL, Castro AF 3rd, Feldman HI, et al. A new equation to estimate glomerular filtration rate. Ann Intern Med. 2009;150:604-12.

22. Improving Global Outcomes (KDIGO) CKD Work Group. Kidney Disease: KDIGO 2012 clinical practice guideline for the evaluation and management of chronic kidney disease. Kidney Int Suppl. 2013;3:1-150.

23. Klein R, Klein BE, Moss SE, Cruickshanks K, Brazy PC. The 10-year incidence of renal insufficiency in people with type 1 diabetes. Diabetes Care. 1999;22:743-51.

24. Akchurin OM, Kaskel F. Update on inflammation in chronic kidney disease. Blood Purif. 2015:39:84-92.

25. Pou KM, Massaro JM, Hoffmann U, Vasan RS, Maurovich-Horvat P, Larson $M G$, et al. Visceral and subcutaneous adipose tissue volumes are crosssectionally related to markers of inflammation and oxidative stress: the Framingham heart study. Circulation. 2007;116:1234-41.

26. Chung AC, Lan HY. Chemokines in renal injury. J Am Soc Nephrol. 2011;22:802-9.

27. Devi S, Li A, Westhorpe CL, Lo CY, Abeynaike LD, Snelgrove SL, et al. Multiphoton imaging reveals a new leukocyte recruitment paradigm in the glomerulus. Nat Med. 2013:19:107-12.

28. Yu HT. Progression of chronic renal failure. Arch Intern Med. 2003;163(12):1417-29.

29. Machowska A, Carrero JJ, Lindholm B, Stenvinkel P. Therapeutics targeting persistent inflammation in chronic kidney disease. Transl Res. 2016;167:204-13.

30. Tonelli M, Sacks F, Pfeffer M, Jhangri GS. Curhan G; cholesterol and recurrent events (CARE) trial investigators. Biomarkers of inflammation and progression of chronic kidney disease. Kidney Int. 2005;68:237-45

31. Fassett RG, Robertson IK, Ball MJ, Geraghty DP, Coombes JS. Effects of atorvastatin on biomarkers of inflammation in chronic kidney disease. Clin Nephrol. 2014;81:75-85.

32. Haynes R, Lewis D, Emberson J, Reith C, Agodoa L, Cass A, et al. Effects of lowering LDL cholesterol on progression of kidney disease. J Am Soc Nephrol. 2014;25:1825-33. 
33. He J, Le DS, Xu X, Scalise M, Ferrante AW, Krakoff J. Circulating white blood cell count and measures of adipose tissue inflammation predict higher 24-h energy expenditure. Eur J Endocrinol. 2010;162:275-80.

34. Bowe B, Xie Y, Xian H, Li T, Al-Aly Z. Association between Monocyte Count and Risk of Incident CKD and Progression to ESRD. Clin J Am Soc Nephrol. 2017;12:603-13.

Submit your next manuscript to BioMed Central and we will help you at every step:

- We accept pre-submission inquiries

- Our selector tool helps you to find the most relevant journal

- We provide round the clock customer support

- Convenient online submission

- Thorough peer review

- Inclusion in PubMed and all major indexing services

- Maximum visibility for your research

Submit your manuscript at www.biomedcentral.com/submit 